\title{
The social surplus of broadband initiatives in compulsory education
}

\author{
David Parsons \\ The Mind Lab by Unitec \\ Auckland, New Zealand \\ d.p.parsons@massey.ac.nz
}

\begin{abstract}
In 2010, the NewZealand government embarked upon an ambitious programme of broadband infrastructure investment, a process that will continue until at least 2019. Part of this investment is specifically targeted at compulsory education, with initiatives that include bringing fibre connections to the school gate, supporting on-site network upgrades (including wireless) and providing teaching, learning and support services delivered through these networks. Such investments are not made without some projections of the likely rate of return, but calculating return on investment (ROI) in educational broadband is complex, as it encompasses a range of factors. This article reports on an interview-based study engaging a range of stakeholders in educational broadband provision. The study utilises a research model that considers the various elements of social surplus, namely; producer surplus (savings), producer surplus (profit) and consumer surplus (perceived value over and above cost), to explore the elements of social surplus that have been used to define educational broadband ROI calculations and justify the scale of investment. The results indicate that all three components of social surplus are relevant, though the concept of profit can only be seen in the broader context of long term contributions to the economy. A note of caution is that projections of ROI based only on positive returns fail to acknowledge the potential for some innovations to actually increase costs. Further, purely quantitative models do not properly take into account qualitative components of consumer surplus.
\end{abstract}

Keywords: Broadband, education, return on investment (ROI), social surplus

\section{Introduction}

Initiatives to extend broadband Internet access are common worldwide, and governments as well as industry are supporting the deployment of broadband networks. These investments are not just seen as commercial initiatives. The Digital Agenda for Europe, for example, aims to expand broadband access to enhance digital literacy, skills and inclusion (European Commission, 2015.) There seems to be little resistance to the idea that such initiatives have social as well as economic benefits, including the reduction of digital divides. The main focus of debate is therefore the best means to realise these potential benefits of broadband (Bauer, Kim \& Wildman, 2005.) There is also a view that the most effective intervention strategy for enacting broadband policy, in the light of the empirical analysis, is a medium-intervention strategy, whereby governments guide and support, but do not entirely dictate, how broadband access should be expanded (Cava-Ferreruela \&Alabau-Muñoz, 2006.) Cambini \&J iang (2009) broadly classify three regulatory approaches as having regional characteristics, namely; deregulation in the U.S., intervention in East Asia and a middle way between these approaches in the E.U., thus medium intervention may be regarded as a European model. However, it should be noted that Bouras, Giannaka \&Tsiatsos (2009) saw a more diffuse set of exemplars for broadband growth, where European nations were prominent but not exclusive. Nevertheless, supporting synergies between private and public sectors was identified as a best practice. This type of strategy requires cooperation between governments and commercial institutions, particularly in cases where the installation of broadband infrastructure cannot be driven purely by short term profit, such as in education (the focus of this particular study) and regional development. Whenever long term national strategy is impacted by broadband initiatives, it becomes necessary for governments to become co-investors in deployment. In large jurisdictions, some of this type of development may be undertaken by municipal entities 
(Feld et al 2005.) This support from government to industry to achieve desired policy outcomes may also involve ownership and governance changes such as the unbundling of previously centralised infrastructure to encourage competition. This 'private public interplay' has been particularly important in Australia and New Zealand (Given, 2010.)

\subsection{Return on investment and social surplus}

The provision of broadband infrastructure is an expensive undertaking, and neither governments nor corporations are likely to embark on such initiatives without positive return on investment (ROI) calculations. ROI is measured primarily in financial terms, but the source of these finances can be derived from either profit or savings. In addition, these profit and savings calculations (known as provider surplus) are complemented by other types of benefit. Consumer surplus (what something is 'worth' over and above what it costs to consume) encompasses many different definitions of value, which are not always easy to quantify, since these consumer gains are often not directly reflected in higher incomes or increases in GDP. However the value of consumer surplus may include actual financial value to the consumer, for example in savings over alternative options. Consumer surplus is combined with producer surplus to create social surplus, the total cost or benefit of a given investment. Hitt and Brynjolfsson (1996) found evidence for the hypothesis that the consumer surplus created by Information Technology in general is positive and growing over time. Therefore we might expect it to provide a substantial contribution to the overall social surplus projected to be gained from a broadband initiative. Measuring such returns can, however, be complex. For example, rates of return may be 'U-shaped' over a period, showing significant returns only at the early and later parts of an adoption cycle (Holt \&J amison, 2009.) Thus the point at which rates of return are measured may have a large impact on the results of analysis. Some returns are relatively immediate, while others may take years to emerge. A further concern is that producer and consumer surplus must be in balance. Focusing only on consumer surplus leads to inadequate investment, while an emphasis only on producer surplus has negative effects on social welfare (Competition Economists Group, 2015.) Thus the research reported in this article takes account of a range of different factors in identifying the main components of ROI, both short term and long term, in broadband policy and deployment.

\subsection{The New Zealand context}

New Zealand is recognised as a valuable case study in progressive digital legislation (Eaves, 2013.) New Zealand's economy has some unique characteristics but shares others with many developed nations. It has been transformed from an agrarian to a more industrialized, free market economy, but in the process has deepened socio-economic divisions, suffered from mediocre economic performance (Auditor General, 2013) and is heavily indebted internationally (Index Mundi, 2014.) Despite a good education system, this has not led to gains in productivity or innovation, and youth unemployment is high (OECD, 2014.) Major business sectors have historically been in primary products and associated with rural regions, but employment in agriculture has been in decline. Manufacturing remains the largest employer, but real estate provides the largest number of enterprises (Trading Economics, 2010; Statistics New Zealand, 2014.) These problems of changing economic patterns, balance of payments deficits and youth unemployment are challenges faced by large numbers of countries across the world, and radical changes to education are frequently seen as essential to address these challenges. Recent major policy initiatives in New Zealand in the area of broadband-enabled digital teaching and learning, intended to address some of these issues, may thus provide us with globally relevant insights into the value of broadband investment in the education sector.

The New Zealand government's Tertiary Education Strategy 2015-2019 classifies the desired outcomes from tertiary education as being economic, social and environmental. Specifically, it states that:

'this strategy focuses in particular on the economic benefits that result from tertiary education and therefore on employment, higher incomes and better access to skilled employees for business as critical outcomes.' (MoE 2014a.) 
Although this strategy focuses only on tertiary education, these themes resonate across the whole value chain of education, since the tertiary sector does not operate independently of its incoming cohorts from secondary education. The central concern is economic benefit as measured by income, a commonly used measure of the value of education (Psacharopoulos, 1994.) The reference to skilled employees also implicitly references the producer profit generated by higher productivity and possibly also an increased supply of skilled labour, thus reducing its cost due to the effect of supply and demand. Of course there is a tension between higher incomes and a greater supply of skilled labour, which requires increased productivity to overcome (Chang, 2011.)

\subsection{Educational broadband policy implementation in New Zealand}

The study reported in this article focuses not on tertiary education, which has been well connected to broadband infrastructure for many years, but on schools. The reason for this is that the New Zealand government is focusing its current educational technology efforts on connecting all of the country's schools to ultra-fast broadband (UFB.) As part of a larger investment in UFB infrastructure, e-education is one of five points in the government action plan for faster broadband, along with e-health, e-government, e-business and e-development (Commerce Commission, 2012.) Government departments are taking major initiatives in providing national broadband for schools and internal school networks (including wireless.) The overall investment in UFB is $\$ 1.5$ billion, the government contributing $\$ 1.35$ billion with private co-investment (MBIE, 2012.) $\$ 28.2$ million of this sum is for fibre connections from school boundaries into the schools. As a result of this infrastructure build, $97.7 \%$ of schools and $99.9 \%$ of students will receive ultra-fast broadband capability, with the remaining $2.3 \%$ of schools in remote areas given wireless or satellite services (MoE, 2014b.)

The UFB project brings fast internet connections into the school grounds, but does not directly address how that connection may be used inside a school. To address the next stage of broadband provision the School Network Upgrade Project (SNUP) has the objective of upgrading internal school networks, and includes a wireless option (MoE, 2015a.) The estimated cost of these network upgrades, which are mostly funded by the government, with some contribution from schools, is estimated at \$600 per student. New Zealand has around 750,000 school students, so if all schools were upgraded the approximate cost would be around $\$ 450$ million.

A further initiative is the Network for Learning (N4L), a \$211 million government-owned agency tasked with providing teaching, learning and support services on these new broadband networks (MoE, 2015b.) As of March 2015, more than half a million students and teachers were using N4L (Williams, 2015.)

Thus the total technology investment in digital teaching, learning and administration across these three initiatives is somewhere in the region of $\$ 700$ million over a period of 5 years, approximately .5\% of annual GDP (NZTE, 2015.)

Schools that have already been connected to fibre networks have reported positive effects, including better student engagement, improved learning outcomes (especially in literacy), more online collaboration, new distance learning opportunities and more effective assessment and administration (Crown Fibre Holdings, 2013.) The challenge, however is to identify what types of ROI might be embedded in these broad claims.

Given the scale of investment in broadband connectivity and related services specifically targeted at compulsory education (i.e. the school sector) both by the New Zealand government and individual schools (who need to further invest in their own staff and services to take advantage of broadband connectivity) it is important to investigate the assumptions made around the expected returns on this investment. Since education is a complex area where there are many different stakeholders with multiple perspectives, qualitative studies such as the one reported in this paper can capture these varying viewpoints and gain insights into return on investment calculations that are not evident in purely quantitative analyses. 
While the results of the study reported in this article largely support the positive assumptions made about the benefits of broadband in education, they provide a much richer and more nuanced set of insights than the sources cited above. Importantly, they also call into question the extent to which UFB will makea positive contribution to social surplus. The study identifies some areas in which the proposed surplus may be negatively impacted by additional costs and lower than expected returns.

The next section provides a review of the literature in educational broadband investment, various aspects of return on investment in this context and the research questions for the study. This is followed by sections on the research methodology and the results of the study. Section five provides a discussion of these results and presents an extended model of ROI for broadband initiatives in education. The paper concludes with a summary of the main findings and some proposals for future work.

\section{Literature Review}

This review of the literature begins with a discussion around the definition of broadband, particularly within the context of educational provision. It also addresses the components of cost benefit analyses and considers the less easily evaluated aspects of return on investment in educational broadband. Finally it addresses the impact of geography on educational broadband provision.

\subsection{Defining broadband}

The definition of broadband connectivity is not fixed across times and contexts, since both technology and requirements vary over time. The UNESCO report on technology, broadband and education (UNESCO, 2013a) takes as its definition a minimum download speed for public internet access of at least $256 \mathrm{Kbps}$ (kilobits per second.) However, it also notes that speed is the key determinant of the range of educational services that can be offered on line, and that services such as video on demand require much faster speeds of at least $2 \mathrm{Mbps}$ (megabits per second.) Hayes (2011) classifies anything less than 2 Mbps as too slow to be classified as broadband. He defines basic broadband as being between 2 and $12 \mathrm{Mbps}$ and fast broadband as greater than $12 \mathrm{Mbps}$. A further issue is that broadband speeds are normally stated in terms of download traffic, since broadband is generally asymmetric (i.e. upload is slower than download.) This can be an important restriction in the educational context since learning is about the creation as well as the consumption of material, so upload speed can also be a key factor in the value of broadband provision. Hayes' (2011) definition of very fast broadband is that it is not only faster than $20 \mathrm{Mbps}$ but is also symmetric. Recognising the importance of symmetric connections, the New Zealand Commerce Commission (Commerce Commission, 2012) specifies a series of application requirements related to symmetric broadband speeds. At the lower end (500 Kbps to $1 \mathrm{Mbps}$ ) are systems such as web browsing and Voice over IP. However the minimum requirement for remote education is stated as $5 \mathrm{Mbps}$ to $10 \mathrm{Mbps}$ while full online educational services require $10 \mathrm{Mbps}$ to $50 \mathrm{Mbps}$. In particular, high speed symmetric broadband is needed for the two-way traffic of cloud based applications, which are increasingly used by schools, for example Google Classroom (Pappas, 2015.)

In New Zealand, the ultra-fast broadband and rural broadband initiatives aim to provide typical download speeds of up to $100 \mathrm{Mbps}$, with up to $1 \mathrm{Gbps}$ (gigabits per second) in some areas. However, the technologies used to deliver broadband in different areas of the country vary between fibre, cable, VDSL (Very-high-bit-rate Digital Subscriber Line) ADSL (Asymmetric Digital Subscriber Line) and Wireless, meaning different broadband speeds depending on the type of connection (MBIE, 2015.) It should be noted that there are many factors affecting connection speed but, for example, DSL connections are unlikely to deliver more than around $70 \mathrm{Mbps}$, and may be much slower. Wireless broadband speeds also vary considerably depending on technology. 


\subsection{Return on investment from broadband infrastructure}

Return on investment calculations are based on cost benefit analyses. These analyses are quantitative in nature and aim to calculate the financial gains and losses that might result from a particular investment. Such calculations do not necessarily concern themselves with equality of result and distribution of gains (Robson, 2014.) However, government investment in broadband needs to consider as widely as possible the economic, social and environmental impacts of policy. In New Zealand the UFB initiative aims to benefit not just business but also education, health, government and development (Commerce Commission, 2012.) One important component of a cost benefit analysis is to consider whether a given investment will reflect an intermediate reference scenario, whereby the most efficient rollout of services is achieved. This compares with pessimistic scenarios, where development is too slow or too limited, and optimistic scenarios where there is inefficient over-investment (Robson, 2014.) Whilst it is probably too early to make this assessment in the New Zealand context, Newman (2012) reports that current bandwidth provision may be inadequate, suggesting that government and schools may face a pessimistic reference scenario.

As described in the introduction, overall return on investment calculations are based on a combination of producer surplus and consumer surplus, which together provide an overall assessment of social surplus. Cost benefit analyses apply to both consumer and producer surplus, and faster broadband may impact on both. Relevant factors may include better or new use of products, savings in time, travel and transaction costs and improvements in productivity. In addition there may be welfare effects such as reducing the costs of supplying publicly provided private goods such as health and education (Robson 2014.) Education, in particular, may be regarded as a merit good. Merit goods are those that may not have immediate calculable benefits but whose consumption is seen as positive by the state (GomezBarroso \& Perez-Martinez, 2005.) When considering welfare effects, cost benefit analyses are complicated by potential conflicts between economic benefits or waste on the one hand and welfare gains or losses on the other (Robson 2014.)

\subsection{Educational broadband investment}

Investing in broadband provision for education takes account not only of simple cost-benefit analyses but of welfare gains and merit goods. Thus long term policy planning is required, and assessing the likely components of social surplus is particularly important. Although there are direct profit and loss calculations to be made in the school sector, such as the costs of provisioning and technical support staff, education is also a long term investment in the future economy and sustainable social structures. Again, this is internationally recognised. UNESCO's policy guidelines on mobile learning emphasise the importance of providing robust and affordable broadband and mobile networks for education that consider equity, safety, advocacy and resources (UNESCO, 2013b.) Efforts to calculate the return on investment in education as a result of the rollout of ultra-fast broadband networks in New Zealand estimated gains of $\$ 3.6$ billion over 20 years, a figure that includes consumer surplus. The overall benefit of UFB over that period was estimated at \$33 billion (Pullar-Strecker, 2012), so the projected contribution of education is around ten per cent. In the report from Bell Labs and AlcatelLucent New Zealand, which proposed these figures, the main benefits to education of broadband investment were seen as lower costs for skill enhancement (primarily through remote learning,) reduced costs for course materials, savings on field trips and better school attendance (by 25 million pupil-days per year.) The latter estimate was based on assumptions that using remote learning applications and better collaboration between parents and teachers would lead to fewer days of school missed due to sickness and truancy (Alcatel-Lucent, 2012.)

Another perspective to the debate is the potential negative effects of not investing in educational broadband, where the social experiences of students become increasingly disconnected from their educational environment (Rosen, 2014.) Further, where the broadband industry is primarily gaining producer surplus through profit, an approach that mitigates against investment in non-commercial education, there is a consequent negative affect on the overall competitiveness of the economy in international terms (Crawford, 2013.) 
A further consideration from the perspective of government policy is that a hands-off approach from government may lead to schools making their own arrangements at a higher cost, since governments are able to leverage the power of mass purchasing to reduce the overall costs of equipment and connectivity (UNESCO, 2013a.)

\subsection{Return on investment for broadband in education}

UNESCO (2013a) suggest a strong connection between broadband and ICT policies and education worldwide, and that broadband can be an accelerator for equitable progress in many aspects of global society. Underlying this belief is an assumption of consumer surplus that is not part of conventional government statistics, but includes educational or civic benefits that go beyond direct economic measurement (Greenstein \& McDevitt, 2012.) If these benefits cannot be directly measured, how can they be assessed? Crandall \& Jackson (2001), in considering the benefits of broadband in retailing, transportation, home entertainment and health care, asserted that they lacked the tools or vision to properly analyse the benefits in the education sector. Nevertheless there are some areas susceptible to direct financial measures, for example in delivering merit goods such as education, overall economic benefits depend on whether those services are provided efficiently (Robson, 2014.) Hayes (2011) notes some longer term measurable benefits, including increased educational attainment for school leavers, based on exposure to ICT potentially improving examination performance, and the efficiency of online education. However even here there are many complexities, for example the impact of network effects in the use of cloud computing in education.

\subsection{Geographical factors}

The variation in broadband speed received by consumers as a result of the communication technologies used is partly a consequence of geography. The size and topography of a country can make a significant difference to how easy it is to reach the population with fixed broadband, and how many areas can economically be connected using fibre. A number of small island nations have already been able to provide fixed broadband connections to all of their primary and secondary schools, while Uruguay has been able to provide fixed broadband to $95 \%$ of primary schools and all secondary schools. In contrast many other countries, such as Colombia, require extensive wireless infrastructure to be able to provide broadband access to their schools (UNESCO, 2013a.) In New Zealand, although the population is largely concentrated in a few cities, particularly Auckland, there are many remote rural communities. The Rural Broadband Initiative (RBI) aims to provide fixed broadband connectivity to 937 rural schools. In addition, the Remote Schools Broadband Initiative (RSBI) will provide wireless broadband services to New Zealand's 57 most remote schools (Commerce Commission, 2012). New Zealand's mixed pattern of provision, with fibre in the main centres and DSL and wireless covering other areas, provides a geographical model similar to many other nations, thus providing a more relevant international case study than, for example, a small island state (NZRS, 2015.)

\subsection{Research context and questions}

A review of the literature makes it clear that broadband provision is internationally recognised as being potentially of benefit to education. However it is also evident that the estimation of return on investment in the sector is complex, relying as it does on a number of longer term and difficult to calculate components of social surplus. Nevertheless the significant costs involved mean that such questions need to be addressed as accurately as possible. Situating this question in the New Zealand context may prove informative to other nations. The literature shows that the way broadband connectivity is provided to schools varies with geography and national policy, but that New Zealand's complex mix of physical environments and public-private partnership on the European model provides an informative case study for other developed nations.

From a review of the relevant literature, therefore, the following research questions were derived. 
1. What assumptions underlie return on investment projections in the provision of broadband infrastructure to schools?

2. How can the components of social surplus be defined within the provision of educational broadband?

\section{Research Methodology}

Given the discussion around the components of social surplus, which are complex, long term and focused on merit goods, the research questions outlined at the end of the literature review were interpreted as largely qualitative questions. A number of quantitative estimates have been cited in this paper regarding broadband investment in education and expected rates of return. No doubt in time these figures will be confirmed or revised in government reports. What is less evident in the literature is an evaluation of the qualitative aspects of social surplus, despite the fact that much of the literature highlights their importance when dealing with merit goods such as education. To address this apparent lack of prior work, a qualitative interview study was designed to address how broadband policy in relation to the school system in New Zealand might see a return on investment. Figure 1 shows the research model used for the study, derived from the core components of ROI that appear in the literature. In this model, educational broadband policy seeks justification in a return on investment calculation that has multiple components. That calculation needs to be defined by a given set of assumptions that are deemed relevant by policy makers. As previously discussed, the sum of components in the ROI calculation can be termed social surplus, a sum that may be derived from three specific sources; producer profit, producer savings and consumer surplus. The research model was used both to help formulate the semi structured interview questions and also to guide the thematic coding process that was used to analyse the interview data, identifying how different aspects of social surplus might be identified in the context of education-related broadband policy in New Zealand. It is important to note that this research concerns itself with social rates of return, which are used to justify investment in educational services, as opposed to private rates of return, which are concerned with how people invest in their own education. The two are, however, linked, since the higher the level of public subsidy for education, the higher the private rate of return (Psacharopoulos, 1994.) Further, as discussed later, we identified some private rates of return for lower socio-economic groups that were not directly related to formal education but were enabled by investments in educational broadband infrastructure.

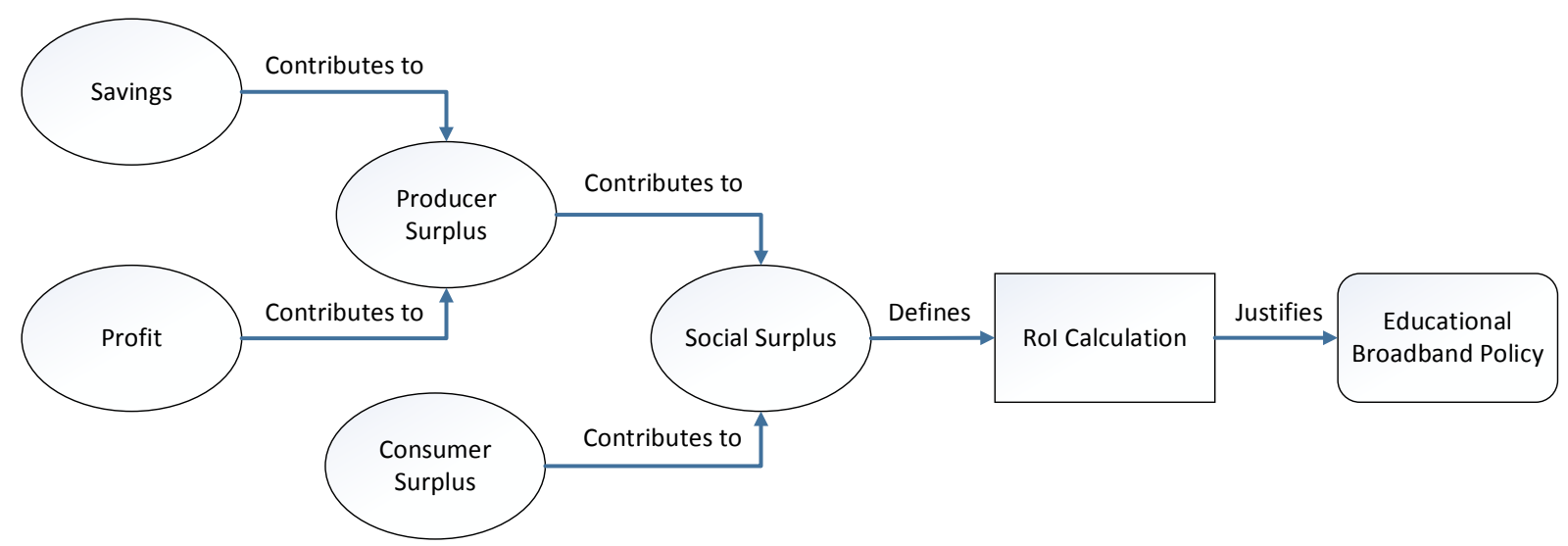

Fig. 1. Research model: ROI for broadband initiatives in education

\subsection{Data description}

The study gathered data from a range of stakeholders from national government, local government, educational institutions and commercial organisations. Since the study was focused on the New Zealand context, all the interviewees were based in New Zealand (Auckland, Wellington and Hamilton.) The purpose of these interviews was to gather the 
perspectives of multiple informed stakeholders in the rollout of broadband to New Zealand schools and to compare these perspectives with the published literature.

A purposeful sample of policy makers and other relevant stakeholders (partly selected via snowball sampling) was chosen from a range of stakeholder institutions, and each of these representatives was interviewed using a semi-structured interview. In total, ten stakeholders were interviewed. Each of these interviews took approximately one to one and a half hours, and was conducted face to face at the interviewee's place of work, where possible (7 interviews.) Where the interviewees could not be met face to face due to location, they were interviewed either by video call (2) or by telephone (1).

The interviewees who contributed to the study represented the following organisations; National Government (Ministry of Education), Local government (Auckland), Secondary School, Commercial Internet Service Provider, Educational Trust, Educational Research Institution, Crown Agency, Industry Organization and Multinational Mobile Communications Provider. The interviews took place in late 2013 and the first half of 2014, with follow up communication via email where necessary.

In the interviews, the stakeholders were asked to respond to a series of semi-structured interview questions around aspects of ROI in educational broadband. In addition to asking general questions around national ICT policy, return on investment, levels of government investment in the broadband market and components of consumer surplus, respondents were also asked to discuss investment in 21st century skills (including digital skills) and matching the skills of school leavers to the employment market. The final question asked them to comment on the future direction of education policy relating to ICT.

\subsection{Data analysis}

Although the research model (Figure 1) has positivist characteristics due to the economic axioms of social surplus, the investigation process took a naturalistic approach, gathering qualitative data from multiple perspectives. The emphasis of the questions was on the social realities of broadband initiatives in education, primarily addressing ' what'-type questions with a fixed set of enquiries. A standard iterative analysis was applied to the data, beginning with data reduction (the interviews were recorded, transcribed and coded in NVivo) then seeking meaning through data display (supported by NVivo tools), and finally drawing some conclusions from the data (Folkestad, 2010.) The main categorical variable in the data was the type of institution represented by each stakeholder.

\section{Results}

The results of the interviews are presented here within the main components of the research model. First, producer surplus derived from savings is addressed, followed by producer surplus derived from profit. Then, consumer surplus is addressed. Finally, their relative contribution to social surplus is considered, along with private rates of return that were not included in the original model but emerged from the data.

\subsection{Producer surplus (savings)}

Given that state supported education is not directly intended as a profit generating enterprise, most of the producer surplus in providing broadband access to schools is in potential savings. In this context, the primary producer is the government who are investing in infrastructure, measuring savings against what would be projected expenditure in the absence of broadband investment. The aspect of savings explicitly stated in the five point government action plan for faster broadband is shared procurement of internet access education services at a better price for schools (MBIE, 2011.) Reinforcing this message, the central government representative in the interview study emphasised the benefits of centralised procurement to drive down costs,' which they estimated at twenty per cent of the overall return on investment.

It may be, however, that such centralised procurement may not always lead to the projected savings, because of the way that schools manage their own procurement policies: 
'Schools don't typically like central control. There's an all of government scheme for purchasing computers. We've got two and a half thousand odd schools, less than thirty have signed up, and yet it's cheaper. They like to do their own thing.' (Internet Provider)

Another potential issue with the projection of savings from centralised procurement is the degree of specification. This can be either too little or too much depending on your point of view. For example one comment was made regarding the implementation of the broadband network itself, suggesting that higher specifications could have been considered;

It would've been useful to have had a little more input from the market ... seems a little like we've undercooked it' (Crown Agency)

This implication of a pessimistic reference scenario echoes comments referenced earlier from Newman (2012.) Nevertheless, UFB investment is expected to raise NewZealand from its 2013 ranking of 27th in the world in terms of Internet speeds and 24th in overall broadband quality, with fibre internet speed 10 to 20 times greater than many current copper connections (Crown Fibre Holdings, 2013.) There is also a trade off in terms of investment between reaching extremely high speeds in some places (e.g. one gigabit per second) or reaching a guaranteed minimum speed across all connections, such as the European Commission's goal of $100 \%$ coverage of at least 30 Megabits per second (Shankland, 2014.) As discussed in the literature review section, broadband provision in New Zealand will rely on a range of different technologies, not just fibre, and the most remote areas will have wireless connections. The investment tradeoffs mean deciding where the boundaries will lie between fibre and copper connections, and between fixed and wireless connections. The government plans for education thus follow the European model of guaranteeing a minimum speed across all connections.

From the other perspective, that centralised procurements may be over-specified, a comment regarding the procurement of on-site network systems for schools stated:

'Some of the ministry schemes are totally over specified..the school is paying $20 \%$ of something they shouldn't be paying for' (Internet Provider)

This seems to indicate an optimistic reference scenario, albeit in a different context (Robson, 2014.) It is worth noting, therefore, that centralised procurement may impact not only on the performance of the systems that are being used, but also on their costs, impacting negatively on the savings component of the producer surplus.

Another area where savings were identified was 'Streamlining school administration, moving a lot of school systems onto the cloud' (Local Govt.) In fact the potential saving 'around streamlining and making administration easier for schools' was estimated at around thirty per cent of the overall ROI by the national government stakeholder. This reduction assumes savings in the overhead of supporting in-house systems, for example hardware, software and support staff costs, by using cloud-based infrastructure. Even more basic savings, such as a reduction in printing costs, also make a contribution.

'Our policy is taking away the paper ... we won't print our reports any more and we won't even e-mail them. You've got to come and get them off our network, and you can get them any time you like' (School)

It should be noted at this point that one might regard cost savings within schools as part of the consumer surplus rather than producer surplus. However, given that schools are government funded, and the ultimate consumers are the students within the schools and their families, school savings are included here as part of the producer component of surplus. Either way they contribute to social surplus.

Part of the hardware and software savings are based on the ability of a broadband wireless infrastructure to support a bring your own device (BYOD) policy in schools. Using student owned devices reduces the need for schools to provide ICT hardware and software for their pupils. 
Reduction of overheads was also identified in terms of the way that teaching and learning could be provided in rural schools:

'One of the immediate benefits [of a fibre network] was to reduce the number of hours that kids spent on buses being shipped from one school to another so they could receive specialist teaching' (Crown Agency)

Another aspect of savings is the availability of free resources on line.

It's all here, it's on YouTube, it's on other people's blogs and Twitter, join the Google+ communities. It's all here, you've just got to access it.' (Trust)

It should be noted, however, that the interviewee here was not addressing all educational resources, but speaking in particular about a set of specific resources for teachers. There is another aspect to the cost of resource access, which is that in some cases the move from older media to online resources may in fact be more costly over time.

The school has a $\$ 10,000$ spend a year, say, on textbooks, where we get five years of use. The model the publishers are talking about the moment is; we will giveyou access to our textbook for one year and then it disappears, which adds up to a lot more than $\$ 10,000$. Much more expensive' (School)

Thus, again, we cannot count on a move towards a UFB infrastructure as representing opportunities to generate savings regardless of content. There may, in fact, be additional costs.

If savings are being made, they are more likely to be madeby providers of educational material:

From a cost perspective once you create a piece of mobile learning you can put it out to people with a one off cost' (Mobile Provider)

Such providers need not, of course, be third party enterprises. However, the likelihood of material developed by teachers independent of professional publishing houses being generally useful is questionable:

'from a system of publishing and editing that has filters, interventions, changes and modifications to a more individual thing, probably the finished product will be much more varied, from absolutely brilliant to; this works well in my class but it doesn't work for anyone else' (School)

From the responses of the interviewees, it can be seen that the role of savings in the producer surplus is expected to make a major contribution to the overall return on investment. In some areas, such as the reduction in printing costs, BYOD programmes and elimination of some travel, savings can be easily identified. However, it is clear that savings from activities such as centralised procurement and use of digital resources are by no means automatic, and in some cases there may in fact be increased costs rather than savings. It should also be recognised that savings might impact on the consumer surplus. For example parents who have to buy a digital device to support a BYOD programme may have a reduced assessment of overall value, and students whose face to face experiences are replaced by virtual experiences may again feel a loss of value. Related issues are highlighted by Newman (2012) who notes that a BYOD policy does not mean existing hardware in schools is no longer required, since BYOD provides only a complementary function and whether schools choose to become "hardware schools" or "Web schools", they will still have to maintain multiple infrastructures in the short term.

\subsection{Producer surplus (profit)}

Estimating profit from state-sponsored education may not be directly relevant, but in the broader national perspective there is a potential contribution to future productivity and downstream profits though support of the knowledge economy.

The return on investment is a better educated, better prepared, graduating cohort' (School) 
Including this aspect of return from a profit perspective assumes that education can make a direct contribution to the economic well-being of the nation. Producer profit from a government perspective is therefore predicated on higher tax incomes and a more economically productive economy. Certainly the most relevant aspect of this is the readiness of those graduating from education to make a contribution to the economy. One area where it is possible to directly identify a contribution is in ensuring that graduating students have relevant digital skills. It is recognised that there is a shortage of skilled ICT workers in New Zealand.

Right now we have a deficit of 15,000 [IT people] how do we actually urgently and directly fix this situation? Or do we forget about being a technology enabled country?' (Industry)

Certainly the provision of broadband into educational institutions is one of many key enablers for ensuring that the New Zealand IT industry is able to find the staff that it needs in the future. If course it is not the only one. Pilkington (2008) notes that it may take time for teachers to begin to fully leverage ICT in teaching and learning. There is also the possibility that, as ICT use becomes the norm in schools, lessons to specifically teach ICT skills will actually feature less on school timetables (Underwood et al., 2005.) Broadband provision is just the first step in the skills value chain, but actual returns are dependent on further developments in curricula, teaching and learning (UNESCO, 2013a.)

In seeking to measure such outcomes, there is a general acceptance that social investment in education yields a social rate of return and that higher levels of education in general are reflected in higher earnings (Psacharopoulos, 1994.) It is also clear that the IT profession is relatively well paid in New Zealand, where it was the second highest paid profession in 2014 (Newson, 2014.) Investment in educational broadband makes a direct (if partial) contribution to preparing the foundation for such careers. There are, however, some further concerns here. It is not clear to what extent higher earnings directly impact on national productivity (Psacharopoulos, 1994.) There is also a concern that more technologically developed economies may actually need fewer educated people as a result of mechanisation (Chang, 2011.) Ultimately; 'what really matters in the determination of national prosperity is not the education levels of individuals but the nation's ability to organise individuals into enterprises with high productivity' (Chang, 2010, p.179.)

Thus we might conclude that, whilst educational investment overall might not always contribute to productivity, specific forms of investment that prepare future workers for productive enterprises, such as broadband infrastructure, can indeed support national prosperity. It is essential that school students are made familiar with the world of technology that they will meet in the workplace;

For our learners to be able to move confidently into the workplace they need to be at home in the digital world' (Trust)

No one is going to wake up on Monday morning and turn the Internet off. The world is moving that way, so it's ensuring all young peopleare moving that way as well...the payback is how successful we are in terms of the economy in the world.' (School)

This doesn't just mean delivering specific technical skills that may or may not be demanded by a particular employer, but a broad, contemporary skill set that is aware of the relevance and use of technology.

Most schools are in urban environments. The kids are going to go all over the place, so we can't predict a particular industry. It's got to be confidence, responsibility, "technology doesn't faze me"' (School)

An important aspect of this preparedness of entrants to the workforce for using technology is that the level of education of the population is a critical enabler for all internet and high technology applications (Koutroumpis, 2009.) However we should also note that according to 
Psacharopoulos (1994) the social rate of return of education in technical and scientific areas is actually lower than that for academic and general areas.

In analysing the results of the interview data related to consumer surplus (profit) it is clear that this is difficult to measure in the short term, but there is a general consensus that education is critical to a technologically developed economy. However, education alone is not the only factor, indeed specifically technical education may not be as important in deriving long term rates of return as the provision of a broad contemporary skill set. Ultimately, profit will be dependent on education being able to support the creation and sustenance of productive enterprises. One of the aims of the evolving digital school curriculum is to foster the kinds of creativity that can meet the needs of future enterprises.

'enabling those kids to express themselves and really create away and be able to get credit for it ... and then find a pathway into further study or out into the workforce' (Govt.)

Of course such reductionist views might be anathema to those to see education as much more than just preparation for the workforce. It should therefore be noted that these reflections are confined to the producer surplus (profit) element of the research model, and are not intended to address all aspects of educational broadband investment.

\subsection{Consumer surplus (social rates of return)}

The research model in Figure 1 assumed that consumer surplus, in the context of this study, would be founded on social rates of return. However, the interview data indicated that private rates of return were also an important factor. In this section, social rates of return are discussed, with private rates of return covered in the following section.

It might well be expected that consumer surplus has a large role to play in calculating the social surplus of investment in education. As indicated previously, in this study the primary 'consumer' is the school student, though as will be seen from some of the results, the concept of consumer also includes wider society. According to the central government interviewee, half [of the ROI is] within improved teaching and learning ... leading therefore to better student outcomes.' (Govt.)

If half the projected ROI from educational broadband is consumer surplus in the context of teaching and learning, this is a significant area for investigation if we wish to identify the specific details of these ROI assumptions. There is certainly a belief that UFB brings new opportunities that were not possible in a more traditional learning environment.

'Opportunities for learning as a young person are exponentially improved by UFB' (Trust)

However, it is important that we seek to identify specific areas where broadband investment is bringing additional value to the consumer. One aspect that certainly gets attention is improvements the personal efficiency of educational delivery. For example,

[After the Christchurch earthquake] the school itself wasn't functional but people would get on the Internet and return to study' (Local Govt.)

Another perspective on efficiency was that students who needed to be away from school for family or sporting events would be able to maintain their studies.

Taking time out of school to go somewhere special, to be part of a sports competition, a special holiday with parents.. now students can do that knowing that they can just access the work easily, so in terms of mobility of students and parental decisions. . that will become a lot easier for parents and kids to do.' (School)

The question that may be raised by such concepts of efficiency is whether more is necessarily better or, perhaps more accurately, whether learning anywhere, anytime, is equal to learning in a classroom with peers and a face to face teacher. It is notable that education is one area where 'output' increases markedly as a result of broadband. Koutroumpis (2009) relates this 
specifically to broadband enabling e-learning. One of the underlying assumptions is that there are direct benefits in terms of personal learning efficiency in situations where peers and teachers are not so significant, that is, in the context of immediate problem solving.

If you can get better access to information then you're going to be able to solve problems or educate yourself with it...10-15 years ago you had to go to library. Now I have that in my pocket.' (Mobile Provider)

Of course the transition to digital provision of material does not just mean using a different channel to deliver the same content. There is also an expectation that a broadband infrastructure enables the provision of better, as well as more accessible, learning resources and tools.

'Moving a lot of school systems onto the cloud...gives you richer systems' (Local Govt.)

Another important perspective is the potential benefits to wider society of improvements in the behaviour of school age children.

Kids come to school early. There is a decline in truanting, in in-class off-task behaviour and other anti-social things' (Govt.)

In previous sections addressing components of producer surplus we have seen that not all changes enabled by broadband infrastructure necessarily result in surplus. In fact, there may be the potential to actually increase costs. In the context of consumer surplus, that may also be the case. Changes to educational processes and tools may impact negatively on existing value chains. For example, old modes of assessment will soon be outdated.

In about five years students will be able to do their assessments online any time they feel like it so that has huge implications for how the learning in schools is structured' (Researcher)

Such changes in structure may be beneficial to students, but equally they may put additional pressures on schools. Radical change also impacts on the systems that educate staff, as well as students;

I think it changes the whole nature of how we train teachers' (School)

In fact, such changes might lead to consumer surplus, but at the cost of producer surplus, in that major change to systems of assessment and teacher training will be expensive to implement. Again, one important message is that surplus is not automatic, or at least may vary by context. Here, we might refer again to Holt \&J amison (2009) and the U-shaped' rates of return, where transition costs may be high.

\subsection{Social surplus (private rates of return)}

In analysing the interview data, it became clear that for a certain section of the community, those who were otherwise disadvantaged in society by their socio-economic status, private rates of return were an important benefit derived from some intended side effects of educational broadband provision. These side effects were generated by certain initiatives that have seen broadband infrastructures installed on school sites being extended to serve their surrounding communities, linked with access to digital devices that were primarily intended for educational use but also find their way into the hands of family members of school students.

Theflow on effect for our lowest socio-economic community is that suddenly they are able to access a whole world that they were never able to before..it's life changing' (Trust)

One effect of this on private rates of return is the ability of low income families, given access to school based community broadband and educational digital tools, to shop on line and thus save themselves money. By such means, UFB can directly reduce digital divides.

Making the Wi-Fi the schools have available in some way for the community to use so that poverty itself doesn't become an impediment' (Researcher) 
In expanding on this comment, the interviewee noted that community access to broadband provided equity in access to knowledge. Such positive effects, however, comprise only small steps towards long term equity, which cannot be provided only by current UFB investments. Nevertheless, an awareness of the relationship between strategic investment and private rates of return for disadvantaged communities will help us to effectively plan future investment.

It'll take generations to truly resolve the inequity of experience or the inequity of outcome across our society and across demographics so the further forward we can look the better' (Crown Agency)

\section{Discussion}

This article has addressed issues surrounding ROI for broadband infrastructure in the New Zealand school system, as revealed by a series of semi structured interviews with relevant stakeholders. A study of ROI in a field like education is intrinsically difficult, because ultimately the outcomes of education are personal.

ROI is probably one of the most unquantifiable of all - what you're doing is providing an opportunity' (Researcher)

Nevertheless, there are some useful concepts in the literature that can be used to make such calculations. The first research question addressed in the research was What assumptions underlie return on investment projections in the provision of broadband infrastructure to schools?' This question was implicit in the literature review, which provided the basis for the research model and the interview questions. As a result, the study was based on a research model which focused on social surplus as the prime driver for ROI in educational broadband policy. However it is clear from the analysis that such a simplistic model fails to address all of the relevant factors. From the results of the interview data, it has become clear that ROI calculations of both producer and consumer surplus involve complex relationships of cost and benefit. Cost and benefit calculations may vary in their timescales and impacts, and vary from the easily calculated to the somewhat speculative. In particular, it is hard to quantify consumer surplus, though this is regularly used by industry in calculating overall social surplus (e.g. Alcatel-Lucent, 2012; Competition Economists Group, 2015.)

The second research question was 'How can the components of social surplus be defined within the provision of educational broadband?' An analysis of the interview data led to a redefinition of the original research model. Figure 2 shows this modified model, developed from the earlier model but incorporating the outcomes of the study. A new component in the model is a separate assessment of social and private rates of return when considering consumer surplus. For each component in the model, the positive and negative forces on surplus that emerged from the interview data have been indicated.

In the savings component of producer surplus, procurement, resources and overheads were identified as key areas of importance, with costs of procurement and resources in some cases potentially leading to negative returns. Profit calculations are long term, and can only be measured by the employability and earnings of students when they enter the workforce. One of the difficulties here is predicting skills demand in an unknown future, so broad rather than narrow skills sets are important.

In assessing consumer surplus, components of social rates of return are largely positive, based around teaching and learning, behaviour and equity, though there are concerns about the long time scales required to truly address inequity. Nevertheless, the impact on private rates of return was seen as very positive for the most disadvantaged members of the community, which was an encouraging finding from the study. 


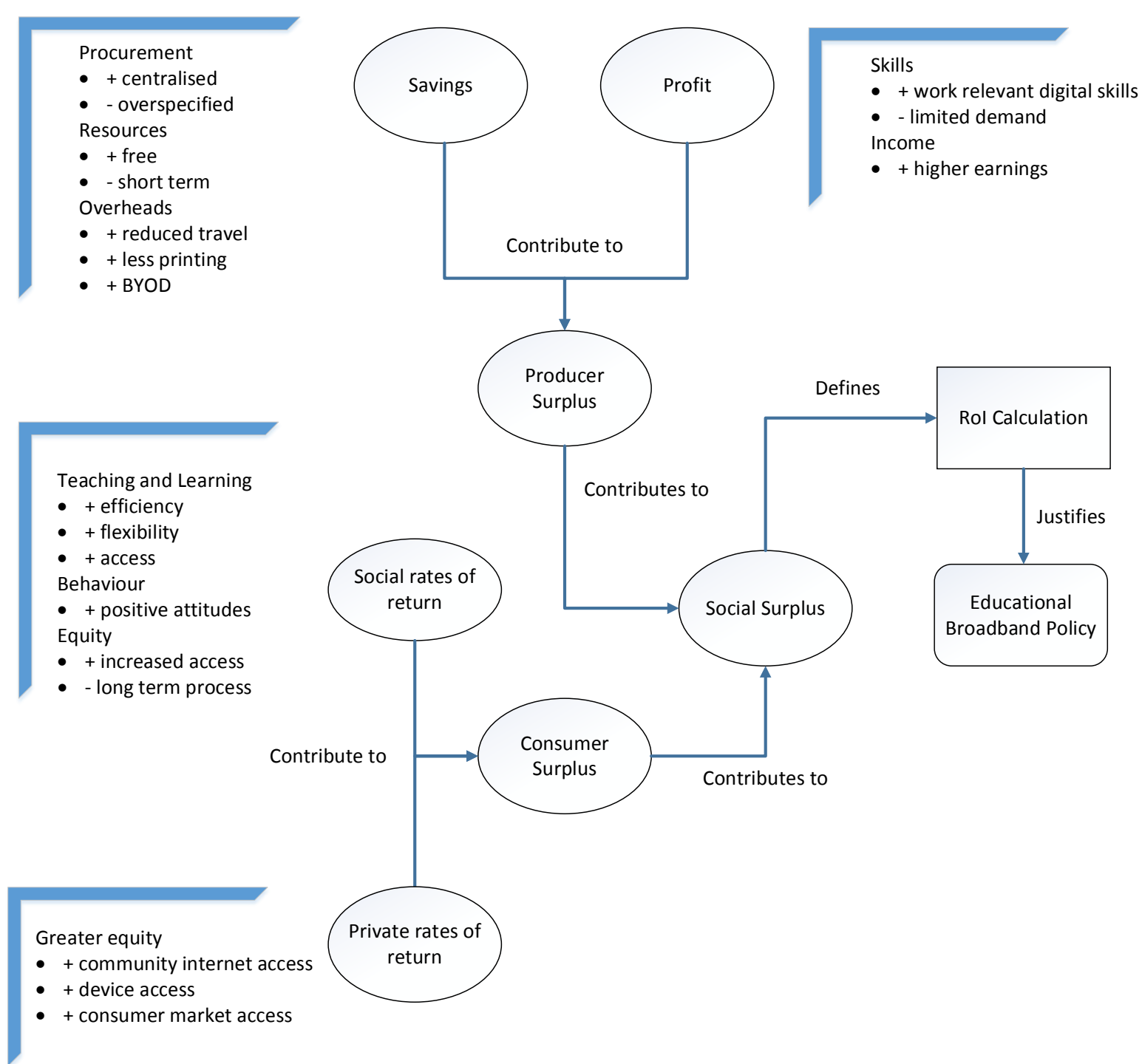

Fig. 2. Extended model of ROI for broadband initiatives in education

\section{Conclusions and Future Work}

Estimates of ROI for educational broadband focus on areas such as increasing access to digital learning materials, reducing the costs of producing and distributing such material, reducing the need for travel and improving student engagement and attendance. The results of this study generally support the main ideas underlying these assumptions. There are certainly savings to be made in the provision of learning materials and richer interactions between teachers, students and parents supported by broadband infrastructure. The study has also identified further important benefits, such as resilience to natural disasters and moreflexibility for family experiences. However, it has also revealed some areas where there may be negative impacts on producer surplus, such as increased costs for professionally published learning materials, or unsuitable central provisioning. There is also a potential negative impact on consumer surplus where new channels of delivery may not be considered to have increased value by the consumer. For example the idea that savings can be made by reducing the need for field trips stresses quantitative gains while ignoring potential qualitativelosses. Most of the analysis was based on the social rate of return within the consumer surplus. However, one important finding from the study was that associated impacts on the private rate of return for the lowest socio-economic groups shows that educational broadband investments can have a positive effect on digital divides. 
In summary, this article has provided deeper and richer insights into the various components of social surplus associated with educational broadband investment than previously available material. It has identified both positive and negative effects within the overall calculations of ROI. In so doing it raises some significant questions about the nature of ROI projections for broadband in education that tend to emphasise gains but ignore potential losses. It is hoped that these findings will help to inform relevant stakeholders about the key issues of concern in gaining the most benefit from the national investment in broadband infrastructure.

This work was based on a qualitative analysis of social surplus. Future work might usefully leverage the model developed from this research to provide more insights into quantitative rates of return for broadband investment in the school sector.

\section{Acknowledgements}

The author wishes to thank the interviewees who gave their time and expertise to this study.

\section{References}

Alcatel-Lucent. (2012) Building the Benefits of Broadband: How New Zealand can increase the social \& economic impacts of high-speed broadband. Available at: http://www.tmcnet.com/ tmc/ whitepapers/ documents/ whitepapers/ 2013/ 6687-

building-benefits-broadband-how-new-zealand-increase-social.pdf

Auditor General. (2013) Public sector financial sustainability. Available at: http:/ / www.oag.govt.nz/ 2013/ financial-sustainability/ docs/ public-sector-financialsustainability.pdf

Bauer, J ., Kim, J . \& Wildman, S. (2005) “An integrated framework for assessing broadband policy options", Michigan State Law Review, 21

Bouras, C., Giannaka, E. \& Tsiatsos, T. (2009) "Identifying best practices for supporting broadband growth: Methodology and analysis", J ournal of Network and Computer Applications, 32:795- 807.

Cambini, C. \&Jiang, Y. (2009) “Broadband investment and regulation: A literature review”, Telecommunications Policy, 33:559- 574.

Cava-Ferreruela \& Alabau-Muñoz. (2006) "Broadband policy assessment: A cross-national empirical analysis" Telecommunications Policy, 30(8).

Chang, H-J . (2011) 23 Things They Don't Tell You About Capitalism, Penguin, London.

Commerce Commission. (2012) High Speed Broadband Services Demand Side Study: Final Report. Wellington: Commerce Commission New Zealand. Available at: http:// www.comcom.govt.nz/ dmsdocument/ 8917

Competition Economists Group. (2015) Welfare effects of UCLL and UBA uplift. Available at: http:// .comcom.govt.nz/ dmsdocument/ 13038\&ei=jd07Vdz5C5D18QWs4oGQDg\&usg =AFQjCNE2BeG8MA5V0WKe128Tc5ePVh7-CA\&sig2=J FTg3Kr_RdP_wu3tji4f6g

Crandall, R. W., \& Jackson, C. L. (2001) “The \$500 Billion Opportunity: The Potential Economic Benefit of Widespread Diffusion of Broadband Internet Access". Washington: Brookings Institution. Available at: http:// www.att.com/public_affairs/broadband_policy/ BrookingsStudy.pdf

Crawford, S. (2013) Captive Audience: The Telecom Industry and Monopoly Power in the New Gilded Age, Yale University Press.

Crown Fibre Holdings. (2013) Fact Sheet: Agreement with Enable Networks. Available at: http:/ / www.crownfibre.govt.nz/ media/ 13092/ fact\%20sheet\%20\%20agreement\%20with\%20enable\%20networks.pdf 
Eaves, D. (2013) New Zealand - The World's Laboratory for Progressive Digital Legislation. Tech President. Available at: http:// techpresident.com/news/wegov/24353/newzealand-worlds-laboratory-progressive-digital-legislation

European Commission. (2015) Digital Agenda for Europe. Available at: http:// ec.europa.eu/ digital-agenda/

Feld, H., Rose, G., Cooper, M. \& Scott, B. (2005) Connecting the public: The truth about municipal broadband. Available at: http:// www.freepress.net/ sites/ default/ files/fplegacy/mb_white_paper.pdf

Folkestad, B. (2010) Analysing Interview Data: Possibilities and challenges. Eurosphere working paper $13 . \quad$ Available at: http:// eurospheres.org/files/2010/ 08/ Eurosphere_Working_Paper_13_Folkestad.pdf

Given, J . (2010) 'Take your partners: Public private interplay in Australian and New Zealand plans for next generation broadband", Telecommunications Policy, 34(9):540-549.

Gomez-Barroso, J . \& Perez-Martinez, J . (2005) “Public intervention in the access to advanced telecommunication services: Assessing its theoretical economic basis", Government Information Quarterly, 22:489 - 504

Greenstein, S., \& McDevitt, R. (2012) "Measuring the Broadband Bonus in Thirty OECD Countries", OECD Digital Economy Papers, No. 197.

Hayes, R. (2011) "Valuing Broadband Benefits: A Selective Report on Issues and Options", Melbourne: Melbourne Business School. Retrieved from https:// web.archive.org/ web/ 20121210000640/ http:/ / broadband.unimelb.edu.au/ eng age/ pubs/ wp/ValuingBroadbandBenefits.pdf

Hitt, L. \& Brynjolfsson, E. (1996) "Productivity, Business Profitability, and Consumer Surplus: Three Different Measures of Information Technology Value”, MIS Quarterly, 20(2):121142.

Holt, L. \& Jamison, M. (2009) "Broadband and contributions to economic grouth: Lessons from the US experience", Telecommunications Policy, 33:575- 581.

Index Mundi (2014) New Zealand Economy Profile 2014. Available at: http://www.indexmundi.com/new_zealand/ economy_profile.html

Koutroumpis, P. (2009) "The economic impact of broadband on growth: A simultaneous approach" Telecommunications Policy, 33(9):471- 485.

MBIE. (2011) Five point government action plan for faster broadband: e-Education. Ministry of Business, Innovation and Employment. Available at: http:// www.med.govt.nz/ sectors-industries/ technology-communication/ fastbroadband/government-action-plan-for-broadband/ e-education

MBIE. (2012) Background and implementation of Ultra-Fast Broadband Initiative. Ministry of Business, Innovation and Employment. Available at: http:/ / www.med.govt.nz/ sectors-industries/ technology-communication/ fastbroadband

MBIE. (2015) Fast broadband: New Zealand's internet upgrade. Available at: http:// www.mbie.govt.nz/ info-services/ sectors-industries/ technologycommunications/ fast-broadband

MoE. (2014a) Tertiary Education Strategy 2014 - 2019. Available at: http:// www.education.govt.nz/ ministry-of-education/ overall-strategies-andpolicies/tertiary-education-strategy

MoE. (2014b) Learning with digital technologies. Ministry of Education. Available at: http:// www.minedu.govt.nz/ theMinistry/ EducationInitiatives/UFBInSchools.aspx 
MoE. (2015a) N4L Managed Network. Ministry of Education. Available at: http:/ / www.minedu.govt.nz/ theMinistry/ EducationInitiatives/ UFBInSchools/ ANetwo rkForLearning.aspx

MoE. (2015b) School Network Upgrade Project (SNUP). Ministry of Education. Available at: http:// www.minedu.govt.nz/ NZEducation/ EducationPolicies/ Schools/ Initiatives/ ICTI nSchools/ICTInitiativesAndProgrammes/ICTInfrastructure/ SNUP.aspx

Newman, E. (2012) High speed broadband services demand side study: Issues paper 2 - e Health and e-Education. Wellington: Commerce Commission New Zealand. Available at: http:// www.comcom.govt.nz/ assets/Telecommunications/Studies/ UFB-DemandSide/ Issues-paper-2-e-health-and-e-education-J anuary-2012.pdf

Newson, R. (2014) Where to work if it's money you're after. The New Zealand Herald, Aug 6, 2014. Available at: http://www.nzherald.co.nz/ personalfinance/ news/article.cfm?c_id=12\&objectid=11304473

NZRS. (2015) National Broadband Map, Available at: https:// broadbandmap.nz/

NZTE. (2015) Statistics. New Zealand Trade and Enterprise. Available at: http:// www.nzte.govt.nz/ en/ invest/ statistics/

OECD. (2014) Country statistical profile: New Zealand. Country statistical profiles: Key tables from OECD. Available at: http:/ / dx.doi.org/ 10.1787/ csp-nzl-table-2014-2-en

Pappas, C. (2015) What Can Google Classroom Offer To The World Of eLearning? eLearning Industry. Available at: http:/ / elearningindustry.com/ google-classroom-a-free-learningmanagement-system-for-elearning

Pilkington, R. (2008) 'Measuring the Impact of Information Technology on Students' Learning", in Voogt \& G. Knezek (Eds.), International Handbook of Information Technology in Primary and Secondary Education (Part One). New York: Springer, pp.1003-1018

Psacharopoulos, G. (1994) "Returns to Investment in Education: A Global Update”, World Development, 22(9):1325-1343.

Pullar-Strecker, T. (2012) Huge payoff from ultrafast broadband predicted. Business Day. Available at: http:/ / www.stuff.co.nz/ business/industries/ 6450713/ Huge-payoff-fromultrafast-broadband-predicted

Robson, A. (2014) Cost-Benefit Analysis of Public Investment in High Speed Broadband Network Infrastructure: An Analytical Framework. Available at: https:// www.communications.gov.au/sites/g/ files/net301/f/5._NBN_CBA_Analytical _Framework_Final_16_May_2014.pdf

Rosen, D. (2014) The School Broadband Scam. Counterpunch. Available at: http:/ / www.counterpunch.org/ 2014/ 02/ 07/ the-school-broadband-scam/

Shankland, S. (2014) Fast fiber-optic broadband spreads across developed world. CNET. Available at: http://www.cnet.com/news/ fast-fiber-optic-broadband-spreads-acrossdeveloped-world/

Statistics New Zealand. (2014) New Zealand Business Demography Statistics: At February 2014. Available http:// www.stats.govt.nz/ browse for_stats/businesses/business_characteristics/ Busi nessDemographyStatistics_HOTPFeb14.aspx

Trading Economics. (2010) Employment in agriculture (\% of total employment) in New Zealand. Available at: http:// www.tradingeconomics.com/new-zealand/ employmentin-agriculture-percent-of-total-employment-wb-data.html

Underwood, J ., Ault, A., Banyard, P., Bird, K., Dillon, G., Hayes, M., Selwood, I., Somekh, B. \& Twining, P. (2005) "The impact of broadband in schools", Becta ICT Research. Available 
at:

http://dera.ioe.ac.uk/1616/12/becta_2005_impactofbroadband_report_underwood Redacted.pdf

UNESCO. (2013a) "Technology, Broadband and Education: Advancing the Education for All Agenda", Broadband Commission Working Group on Education. Paris: UNESCO. Available at: http:/ / unesdoc.unesco.org/images/ 0021/ 002196/219687e.pdf

UNESCO. (2013b) UNESCO policy guidelines for mobile learning. Available at: http:/ / unesdoc.unesco.org/ images/ 0021/ 002196/ 219641e.pdf

Williams, S. (2015) 500,000+ students \& teachers using N4L's Managed Network. Techday. Available at: http:// educators.co.nz/ story/ 500000-students-teachers-using-N4LsManaged-Network/ 7a63c8c4-7c19-11e4-bc2b-

0abdbf634b7d/ ?utm_campaign $=20150326 \& u t m \_$medium $=$Email\&utm_source $=$educa tors-news-alerts

Copyright: (C) 2016 Parsons. This is an open-access article distributed under the terms of the Creative Commons Attribution-NonCommercial 3.0 Australia License, which permits noncommercial use, distribution, and reproduction in any medium, provided the original author and AJ IS are credited.

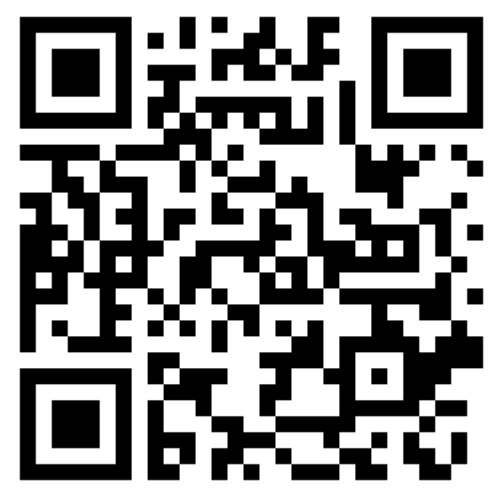

